\title{
Coulisses
}

Revue de théâtre

13 | Hiver 1996

Varia

\section{Andromaque de Jean Racine}

Mise en scène de Jean-Michel Potiron

Lucile Garbagnati

\section{CpenEdition}

Journals

Édition électronique

URL : http://journals.openedition.org/coulisses/4357

DOI : $10.4000 /$ coulisses.4357

ISSN : 2546-9460

Éditeur

Presses universitaires de Franche-Comté

Édition imprimée

Date de publication : 1 janvier 1996

Pagination : 77-78

ISSN : 1150-594X

Référence électronique

Lucile Garbagnati, «Andromaque de Jean Racine », Coulisses [En ligne], 13 | Hiver 1996, mis en ligne le 15 mars 2019, consulté le 01 octobre 2020. URL : http://journals.openedition.org/coulisses/4357 ; DOI : https://doi.org/10.4000/coulisses.4357

Ce document a été généré automatiquement le 1 octobre 2020.

Coulisses 


\title{
Andromaque de Jean Racine
}

\author{
Mise en scène de Jean-Michel Potiron
}

\section{Lucile Garbagnati}

Jean-Michel Potiron est l'animateur du Théâtre à tout prix. Andromaque été créée dans le cadre d'un compagnonnage artistique à l'Espace-Scène nationale du 7 au 10 novembre 1995.

\section{Compte-rendu du débat avec Jean Michel Potiron ${ }^{1}$ :}

à l'Embarcadère, le 10 novembre 1995.

« Andromaque $^{2}$ me fait lever la tête. »

Certains auditeurs avaient assisté au spectacle, d'autres non. Les questions étaient donc complètement ouvertes.

- Pourquoi avez-vous choisi un classique, Andromaque en particulier?

- Andromaque me fait lever la tête., alors que la littérature contemporaine me la fait baisser. Je lis 200 à 300 textes par an. Je m'ennuie. J'ai envie de parler de mon temps. Andromaque parle de notre temps. Je regarde beaucoup les débats et les matches de foot à la télévision. Or je constate que plus on possède le langage, moins on bouge. La violence est exprimée par le langage. L'alexandrin c'est la maîtrise totale du langage et de la rhétorique. C'est une arme.

- Comment avez-vous travaillé l'alexandrin ?

- Je me suis mis en rapport avec Nicole Rouillé professeur de rhétorique à l'université de Liège auteur d'une thèse sur l'alexandrin. L'objectif était de faire sonner l'alexandrin au plus près de la manière dont il était dit au XVII ${ }^{\text {ème }}$, et il sonne vraiment comme à cette époque.

- Comment avez-vous travaillé avec les comédiens qui sont très statiques ?

- Je ne voulais aucun artifice. Je suis resté trois à quatre mois en tête à tête avec le texte à raison d'environ une page par jour de manière à pouvoir donner de la nourriture à l'acteur. Il faut que l'acteur reste spontané par rapport au texte, qu'il soit d'une sincérité totale. L'auteur signe le texte ; le metteur en scène, le contexte ; l'acteur, le sous-texte. 
Les personnages sont écrasés par leurs parents. Chacun court après la gloire de ses parents. Ils sont pris entre la raison d'État et la raison individuelle à la veille d'une guerre civile. Trop de livres excusent Pyrrhus, Barthes ${ }^{3}$ entre autres. Or, Pyrrhus est inexcusable.

- Mais on ne sent rien de royal entre les personnages, même pas que ce sont des hommes et des femmes, ce sont des acteurs désincarnés.

- Je rêve, comme Claude Régy ${ }^{4}$ que [les] choses soient prises pour ce qu'elles sont, qu'il n'y ait ni interprétation, ni symbole.

- Comment avez-vous réglé les déplacements?

- Les répétitions ont duré deux mois. Les acteurs ont réglé eux-mêmes leurs déplacements. Ce que je veux, c'est que le texte soit juste. Les acteurs ont dû occuper cet immense espace du plateau. Si l'acteur vibre vraiment le vide prend sens.

- N'y a-t-il pas une volonté de faire du vide vide?

- Dans leur solitude il doit y avoir une vibration.

- La musique intervient à différents moments, pourquoi?

- Ce n'est pas de la musique c'est de la voix étirée. Le son c'est une recherche sur le questionnement de Dieu. Dieu s'est fait verbe.

- Pourquoi pas de décor?

- Il s'agissait de monter une pièce dans la continuité sans interruption, l'essentiel étant de ne pas surcharger. En effet le mensonge de l'alexandrin suffit. Il s'agit de faire croire que des gens parlent en alexandrins. Rajouter du décor, c'est alourdir le propos.

L'absence totale de décor permet de mettre en évidence la solitude de l'homme. Il y a eu une époque où les dieux descendaient sur terre, mais les dieux n'interviennent plus. L'homme est seul. Les personnages sont tournés vers l'être, pas vers l'avoir, pas vers la vie domestique.

- Mais l'escalier technique du plateau est un décor en soi.

- Le plateau d'un théâtre est à prendre tel qu'il est. J'ai demandé aux comédiens d'être tels qu'ils sont. C'est l'acteur qui fait exister les choses. Ce n'est pas un spectacle qui veut aller vers la théâtralité, mais aller vers les choses essentielles.

- Qu'est-ce que ça veut dire ne pas aller vers la théâtralité ?

1 - C'est prendre le texte au pied de la lettre : l'amour, la haine, la honte. Essayer d'aller le plus loin possible dans la découverte de l'être. L'acteur ne peut pas «faire semblant ». Je voudrais que le théâtre soit la vie.

Le spectacle va s'aboutir devant le public. Le metteur en scène doit alors partir physiquement. Le spectacle devient alors la chose des comédiens et du public. 
Andromaque

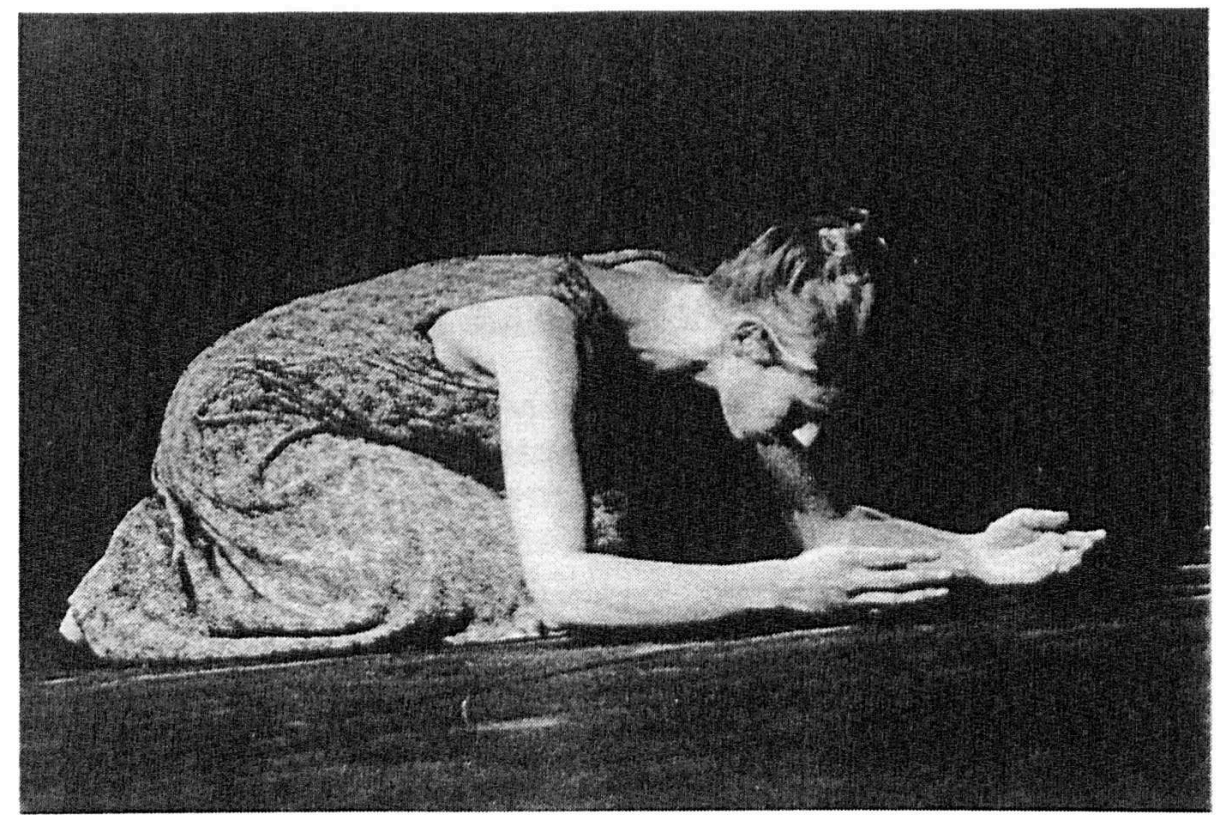

\section{NOTES}

1. Coulisses a publié des critiques des mises en scène de J.M. Potiron. $n^{\circ} 2$, Les fausses confidences, $L a$ dispute de Marivaux sous le titre Marivaux sans marivaudage; Coulisses $\mathrm{n}^{\circ} 5$ Le monte-plats de Harold Pinter (p. 11); Coulisses $n^{\circ} 10$, Kiki l'indien, de Joël Jouanneau (p. 25).

2. A l'occasion de la diffusion de Britannicus dans une mise en scène d'Alain Françon, Coulisses $n^{\circ} 6$ a publié un dossier sur cette tragédie et l'art de Racine.

3. N.D.L.R. : Sur Racine, Le Seuil, Col. Points

4. N.D.L.R.: C. Régy a fait découvrir des auteurs contemporains français et allemands, en particulier Peter Handke et Botho Strauss. Pour lui l'essentiel est hors scène. Il tente de dégager le théâtre de tout aspect naturaliste ; l'essentiel se trouve dans le rapport entre le texte et l'image qu'il dissocie. L'espace théâtral est un espace mental. 